\title{
Isolated congenital anosmia
}

INSERM

\section{Source}

INSERM. (1999). Orphanet: an online rare disease and orphan drug data base. Isolated congenital anosmia. ORPHA:88620

This syndrome is characterised by total or partial anosmia at birth. So far, 15 patients have been described. The anosmia is caused by a defect in the development of the olfactory bulbs or by replacement of the olfactory epithelium by respiratory epithelium. The mode of transmission appears to be autosomal dominant with incomplete penetrance. Isolated congenital anosmia is found in some parents of individuals with Kallman syndrome (see this term). 